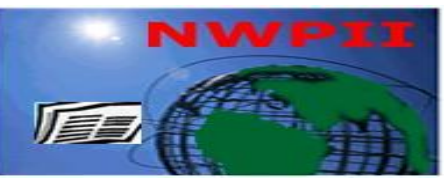

American Journal of Biomedical Sciences

ISSN: 1937-9080

nwpii.com/ajbms

\title{
Therapeutic Impacts of Probiotics - as Magic Bullet
}

\author{
Pooja N. Thakkar ${ }^{1 *}$, Hasmukh A. Modi ${ }^{1}$, Jashbhai Prajapati ${ }^{2}$ \\ ${ }^{1}$ Department of Life Sciences, Gujarat University, Ahmedabad. \\ ${ }^{2}$ Department of Dairy Microbiology, Anand Agricultural University, Anand. \\ "Corresponding Author \\ Pooja Nilesh Thakkar \\ 39/233, Vijaynagar Housing Society, Near Ankur Cross Roads \\ Naranpura \\ Ahmedabad-380013, Gujarat \\ India \\ Phone: +91-9909804647 \\ Email: poojathakkar16603@gmail.com
}

Received: 06 February 2016; | Revised: 05 April 2016; | Accepted: 12 April 2016

\begin{abstract}
Probiotics are the live microbial food/feed supplements which benefit the host when administered in a certain number. Probiotics have been within our domestic use for as long as people have consumed fermented milk, curd, butter milk, but their association with health benefits dates only from the turn of the last century, when Metchnikoff drew attention to the health promoting effects of some gut microflora on the host, and suggested that ingestion of fermented milk products ameliorated this so called auto-intoxication. Species of Lactobacillus, Bifidobacterium, Bacillus, Streptococcus, Lactococcus and Saccharomyces are commonly used as Probiotics. Recently, probiotics are immensely showing fruitful results for the treatment of various diseases and to alleviate the symptoms of many others like diarrhea, pouchitis, cancer, ulcerative colitis, irritable bowel disease, and a host of many others. The complete mechanisms of action of probiotics in disease management and enhancement of the health of the host remain largely unknown, but the major activities appear to be via modulation of immune responses and colonization and competitive shielding off of pathogens. This paper is set to review some of the ailments for which probiotics have been tested. With an upsurge in the use of probiotics, also comes an increase in skeptics on the safety of their use for medical purpose, the safety concerns that may obstruct effective usage, therefore cautious applications of probiotics in disease management necessitate further investigations.
\end{abstract}

Keywords: Probiotic, Lactic acid bacteria, Health, Infection, Disease management.

\section{Introduction}

The human gastrointestinal tract is house to diverse and enormous communities of microorganisms representing over 400 cultivable species. The colonization of the gastrointestinal tract commences instantly after birth. In a healthy adult, the gastrointestinal tract contains 10 times 
as many bacteria $\left(10^{14}\right.$ bacteria) as eukaryotic cells in the entire body [1]; the combined genome of the intestinal flora is estimated to be 50-100 times the size of the human genome [2]. As these organisms are metabolically active and interact continuously with their environment (including other bacteria, the gut epithelium, mucosal immune system, the central nervous system, and the endocrine system), they are able to wield a significant influence on the postnatal development and the host physiology [3]. While a majority of the indigenous flora exhibit health promoting properties, some possess the potential to cause diseases. For example, lactobacilli and bifidobacteria are associated with health, while clostridia are considered detrimental to health. However, when this delicate ecological balance between pro health and anti health is perturbed by environmental or physiological factors, predisposition to infectious and immunoinflammatory disease is enhanced.

Probiotics represent the new buzz word in human dietary portfolio and are currently the major focus of attention across the world due to their enormous health potentials [4]. Probiotics are defined as live micro-organisms which when administered in adequate amounts confer a health benefit on the host most probably by recovering and restoring the microbial balance of gastrointestinal tract [5]. (SENTENCE REMOVED). Most organisms used as probiotics are Lactobacillus and Bifidobacterium, and a few tested strains of nonpathogenic E. coli strains, Saccharomyces boulardii, Clostridium butyricum, and Streptococcus thermophilus and genetically engineered bacteria that secrete immunosuppressive substances such as interleukin-10 [6]. Specific traits that place an organism to be an effective probiotics include acid tolerance, bile tolerance, cell surface hydrophobicity, antimicrobial activity and colonization of gastrointestinal tract [7, 8]. Several research efforts are going on to explain the mechanism of action of probiotics including improvement of gastrointestinal tract health via modifying gut $\mathrm{pH}$; antagonizing pathogens through production of antibacterial compounds and/or competitive exclusions of pathogens at the binding and receptor sites; enhancing the immune system; synthesizing and enhancing the bioavailability of nutrients, competing for available nutrients; reducing the symptoms of lactose intolerance, decreasing the prevalence of allergy in susceptible individuals, and reducing risks of certain cancers through binding of deleterious mutagens and carcinogens and hypocholesterolemic activity $[9,10]$.

A recent study paper by Probiotic Association of India presented a good competition of work done in India including the clinical applications. Several studies demonstrating health effects by in vitro tests, animal feeding tests and human clinical trials were reported [11, 12]. In the present review article we highlight a number of the diseases for which probiotics have been used to manage and ameliorate diseased conditions.

\section{Antidiarrhea effects}

Diarrhea is signal of gastrointestinal illness, which can be rooted by a variety of bacterial, viral and parasitic organisms and it could also be antibiotic associated [13]. Probiotics increases IgA level and other immunoglobulin secreted cells in the intestinal mucosa and stimulate local discharge of interferon which aids antigen transfer to principal lymphoid cells that serve to enhance antigen uptake in Peyer's patches [14]. Probiotics benefit viral diarrhea through increasing antibody secretion and lowering viral shedding, prevent selected intracellular mechanisms involved in viral replication (such as MEK, PKA, p38 MAPK) suggesting an immunological mechanism [15-17].

Antibiotic associated diarrhea (AAD) is a general impediment, perturb the normal microbial flora of GIT, and ultimately result in the production of toxin, leading to diarrhea [18, 19]. Administration of probiotic strains, especially Lactobacillus rhamnosus strain $G G(L G G)$ and Saccharomyces boulardii, before and during antibiotic treatment reduced the frequency and/or duration of diarrhea [20, 21]. In a clinical study, Kotowsha et al., (2005)[22] enrolled 269 children who were taking antibiotics for ear or respiratory infections; randomized them to either Saccharomyces boulardii $(500 \mathrm{mg} / \mathrm{d})$ or placebo 
for the duration of the antibiotic treatment. Even though the follow-up time was short (two weeks post antibiotic), the frequency of diarrhea in the probiotic group was significantly less (3.4\%) compared to $17.3 \%$ in the placebo group. Several meta-analyses have shown reduced incidences of AAD in probiotic treated patients [23, 24]. Clostridium difficile associated diarrhea (CDAD) is most often caused by clindamycin, cephalosporins, ampicillin, and amoxicillin. Total flora replacement or faecal bacterio therapy (using L. acidophilus, L. rhamnosus) has been described as an effective treatment alternative in severe $C$. difficile infections [25].

Well-controlled clinical studies have revealed that probiotics such as L. rhamnosus GG, L. casei Shirota, L. reuteri, and B. animalis Bb12 can shorten the period of acute rotavirus diarrhea [26]. Sur et al., (2011) [27] reported 14\% reduction in acute diarrheal diseases in a study that evaluate the role of a probiotic milk-based beverage (Yakult) in children (aged 1-5 years) in the urban slum of Kolkata $(\mathrm{n}=3758)$. Basu et al., (2009)[28] tested the efficacy of L. rhamnosus GG in controlling acute watery diarrhea in Indian children in a randomized, controlled, hospitalbased study. Dubey et al., (2008) [29] also reported a hospital based placebo-controlled study to assess the efficacy and tolerability of a commercial probiotic preparation, VSL\#3 in the treatment of acute rotavirus diarrhea in children. Residents of developed countries traveling to subtropical and tropical zones suffer increased traveler's diarrhea incidence (3 times or more). Drinking a Lactobacillus GG strain significantly decreased the prevalence of diarrhea in travelers [30].

Prajapati and Shah (2011) [11] reviewed application of Probiotics in animals \& humans and has compiled studies done in India on diarrheal diseases in gut microbiology. The results of the systematic reviews are consistent and suggest that probiotic therapy is safe and effective \& shortens the duration of acute diarrheal illness in children by approximately one day.

\section{Prevention of Helicobacter pylori infections}

Helicobacter pylori is a Gram negative human gastric pathogen, which has a possible etiologic role in peptic \& gastric ulcers, gastric cancer, lymphoma, and several nongastrointestinal disorders. Although antibiotic based $\mathrm{H}$. pylori eradication treatment is $90 \%$ effective, but it is expensive and causes antibiotic resistance associated with other adverse effects. In vitro as well as animal studies demonstrated that probiotic treatment is effective in reducing $\mathrm{H}$. pylori associated gastric inflammation [31]. The use of probiotics to treat $\mathrm{H}$. pylori infection has been proposed for improving the eradication rate, tolerability and for the compliance of multiple antibiotic regimens used for the infection [32]. About 16 studies used probiotics alone as an alternative to antibiotics for the treatment of $\mathrm{H}$. pylori infection $[33,34]$.

Aiba et al. (1998) [35] showed L. salivarius capable of producing high amounts of lactic acid to inhibit the growth of $\mathrm{H}$. pylori in the in vitro studies as well as in mice. L. johnsonii La1 was reported to demonstrate a long-time suppressive effect on $H$. pylori gut colonization when administered as a whey-based culture supernatant [36]. Live and heat-killed L. johnsonii La1 and L. paracasei ST11 were given to $\mathrm{H}$. pylori-infected children for 4 weeks in a double blind, randomized, controlled study, resulted in a moderate decrease of infection [37]. Likewise, administration of live L. casei in milk for 3 weeks offered a slight suppression of $\mathrm{H}$. pylori infection [38]. Similarly, supplementation of yoghurt containing $107 \mathrm{CFU}$ of both B. lactis Bb12 and L. acidophilus La5 twice daily for 6 weeks had reduced H. pylori infection [39]. Similar studies were performed by Datta et al., (2005) [40]; Devi et al., (2007) [41] and Chaturveddi et al., (2010) [42]. Thus, long term intakes of products containing probiotic strains may have a favorable effect on $H$. pylori infections in humans, particularly by reducing the risk of developing disorders associated with high degrees of gastric inflammation. 


\section{Probiotics in Diabetes}

Diabetes mellitus has been described as a metabolic disease associated with a series of multiple risk factors that can be effectively managed by multi factorial interventions including dietary manipulations. Several research findings [43-45], observed that in addition to risk factors such as genetic predisposition, epigenetic changes and unhealthy lifestyle, altered gut microbiota are major risk factors because that cause increased adiposity, cell dysfunction, hyperglycemia, hypercholesterolemia, dyslipidemia, metabolic endotoxemia, systemic inflammation, intestinal permeability (leaky gut) and oxidative stress associated with type 2 diabetes (T2D) and also a major risk factor in type 1 diabetes (T1D) [46].

Probiotics have emerged as the prospective biotherapeutic in improving the altered gut microbial composition and by targeting all the possible risk factors. Calcinaro et al., (2005) [46] reported that orally administered probiotic compound VSL\#3 prevented autoimmune diabetes and induces immunomodulation by a drop in insulitis besides further severity in a mice. In a study conducted by Yadav et al. (2007) [47] , it was found that the administration of Dahi (an Indian fermented milk product) containing $L$. acidophilus, $L$. casei and L. lactis to high fructose-induced diabetic rats for eight weeks decreased the accumulation of glycogen in the liver of rats compared to the control that was not fed the probiotics. The probiotic Dahi supplemented diet significantly delayed the onset of glucose intolerance, hyperglycemia, hyper insulin anemia, dyslipidemia, and oxidative stress in high fructose-induced diabetic rats, indicating a lower risk of diabetes and its complications. Similarly, Ejtahed et al., (2011) [48] accounted that probiotic yogurt improved total cholesterol and LDL-C concentrations in type 2 diabetic people. The beneficial effects of co-consumption of probiotics with oral anti-diabetic sulfonylurea drug (Gliclazide) have extra beneficial pancreatic effects when insulin therapy is unsatisfactory. Such findings, point toward the beneficial effects of probiotics for treating diabetes in synergism with other diabetes drug and thereby reduces the incidence of diabetes related hypertension.

\section{Lactose intolerance}

Lactose intolerance is caused by the deficit or diminished activity of the lactose-cleaving enzyme $\beta$-galactosidase in the small intestine. It affects more than $75 \%$ of the population worldwide and causes abdominal pain, bloating, flatulence, diarrhea, nausea, and acid reflux [49]. This problem might be alleviated by the consumption of fermented dairy products having live probiotic bacteria due to their lower lactose content and the release of $\beta$-galactosidase in the GI tract that can survive digestion [50].

Yogurt found to be unique among other fermented milk products such as buttermilk and sweet acidophilus milk \& well tolerated by lactose intolerant people as the presence of bacteria such as $L$. delbrueckii ssp. bulgaricus and Streptococcus thermophilus in yogurt release $\beta$ - galactosidase in the intestine [51, 52]. Other fermented products such as buttermilk, kefir and ropy milk also had a $20-26 \%$ drop in lactose content $[53,54]$. A clinical human study showed that supplementation with Bifidobacterium longum capsules and yogurt enriched with $B$. animalis was effective in alleviating lactose intolerant symptoms. In a related study on lactose maldigesting children (5-16 years), demonstrated that consumption of milk with L. acidophilus or a commercial yogurt containing $L$. lactis and $\mathrm{S}$. thermophilus reduced lactose intolerance signs compared with the group of children who consumed unfermented milk [55]. Further clinical trials of specific strains and concentrations are necessary to delineate the potential therapeutic effects of probiotics in lactose intolerance.

\section{Probiotics in inflammatory bowel disease}

Inflammatory bowel disease (IBD) is a collective term, used for Ulcerative colitis (UC), Crohn's disease (CD) and Pouchitis. IBD is an abnormal immune response against luminal antigen of commensal bacteria in genetically predisposed individuals. Several clinical trials recommend selected probiotics species, alone or 
in combination, can prevent recurrent intestinal inflammation and possibly treat active IBD [56, 8].

\subsection{Crohn's disease (CD)}

The proposed mechanisms of action of probiotics in the management of Crohn's disease include change in the pattern of short chain fatty acids (SCFA) production; reduction in proinflammatory cytokine secretion, improving TH1/TH2 ratios; eliminating pathogens; enhancement of barrier function [57]. He treated 10 patients of Crohn's disease not responding to 5-ASA and prednisolne therapy with a synbiotic therapy, (Probiotic - Bifidobacterium and Lactobacillus and prebiotic- psyllium), for 12 months and concluded, six patients among twelve went into remission, one had a partial response with improvement of the number bowel movements, and the remaining three patients were non-responders. Therefore, it makes sense either to abolish some bacteria with antibiotics or to alter the gut flora, in favor of more beneficial bacteria, by the use of probiotics and prebiotics [8].

\subsection{Ulcerative Colitis (UC)}

In ulcerative colitis (UC), imbalanced microflora is associated with increased number of pro-inflammatory bacteria, including Enterobacteriaceae, and Bacteroides fragilis lead to reduce count of protective bacteria, including lactobacilli and bifidobacteria. In a double blind study for patients with active UC, Furrie et al., (2005) [58] supplied combination of probiotics strain, Bifidobacterium longum, with a prebiotic composed of an inulin-oligofructose on 18 patients. Nine patients assigned to the treatment group and nine to the placebo group. The patients were treated with the synbiotic mixture twicedaily for 4 weeks. At the end of the month, the patients receiving the synbiotic mixture exhibited reduced mucosal inflammatory markers (significant reduction in TNF- $\alpha$ and IL- $\alpha$ level) in colonic biopsies with the active therapy as compared to placebo. In a study comparing the effect of probiotic Escherichia coli Nissle 1917 versus mesalamine on induction of remission in UC, both groups had similar time to remission, demonstrating equal efficacy of treatments [59, 60].

\subsection{Pouchitis}

Pouchitis is an idiopathic inflammatory illness of the ileal pouch. VSL\#3, a mixture of 8 probiotic bacteria, is effective in maintaining antibiotic-induced remission in patients with recurrent or refractory pouchitis [61]. In a randomized, double-blind, placebo controlled study, 40 patients were randomized within a week after surgery to receive either VSL\#3 or placebo for 12 months. Two of 20 (10\%) of the patients treated with VSL\#3 developed an episode of acute pouchitis compared to 8 patients $(40 \%)$ in the placebo group. Patients treated with VSL\#3 and no signs of pouchitis and had a median stool frequency of 5 (range, 3-9) at the end of the trial compared to 8 (range, 6-12) in the placebo group [62]. Recent clinical studies further showed that VSL\#3 treatment significantly increases the number of mucosal regulatory $\mathrm{T}$ cells in patients with IPAA, indicating a potential beneficial immunoregulatory mechanism of probiotic action in this disease [63]. Addition of VSL\#3 for 6 weeks led to either remission or response in $77 \%$ of patients as measured by the disease activity index [64]. Thus, these findings suggest a potential therapeutic role for probiotics in the treatment of active IBD.

\section{Probiotics in Hypercholesterolemia and Hypertension}

Cholesterol is a precursor to certain hormones and vitamins and is a component cell membranes and nerve cells. However, elevated levels of total blood cholesterol (Hypercholesterolemia) or other blood lipids are considered to be a high risk factor for coronary heart disease, one of the leading causes of death. These cholesterol levels can be brought down using probiotics. The mechanisms can be direct or indirect. Direct mechanism is either inhibiting the de novo synthesis by hypocholesterolemic factors like lactose, uric acid, orotic acid, whey proteins or by decreasing the intestinal absorption of dietary cholesterol by three ways - 
assimilating, binding, and degradation. The cholesterol level can be reduced indirectly by deconjugating the cholesterol by bacterial acid hydrolases to bile acids, thereby reducing the total body pool [65].

Mann (1974) [66] observed that men from the tribes of Samburu and Maasai warriors in Africa showed reduced serum cholesterol level after consumption of large amounts of milk fermented with a wild Lactobacillus strain. Since then, the potential hypocholesterolemic effect of fermented milk products containing lactobacilli and/or bifidobacteria has been investigated in dietary studies using humans and animals. Klaver and van der Meer (1993) [67] studied the mechanism of assimilation of cholesterol by Lactobacillus acidophilus and Bifidobacterium bifidum and concluded that removal of cholesterol was due to co-precipitation with deconjugated bile salts in an acidic environment. Lactic acid bacteria with active BSH, or cultured products containing them, are suggested to lower serum cholesterol levels through an interaction with the host bile salt metabolism [68]. Tahri et al., (1996) [69] studied assimilation of cholesterol by studying intense binding between cell surface and cholesterol, necessary for uptake of cholesterol into the cells. Consumption of probiotics points towards a decrease in cholesterol synthesis by reducing the activity of hydroxyl-methylglutaryl- coenzyme A reductase in the liver. Further, increases in the amounts of fecal bile acids suggest that there is a compensatory increased conversion of cholesterol to bile acids [70].

The potential hypocholesterolemic effects of probiotics sparked much interest based on evidence from animal work and from human studies. A randomized feeding trial comprising 27 human volunteers with both normal lipid profile and hyperlipidemia was conducted by Ashar and Prajapati (2001) [65] by feeding 200 $\mathrm{ml}$ of stirred acidophilus milk $\left(5 \times 10^{8}\right.$ live lactobacilli) for 20 days and observed significant reduction by $7.6 \%$ in total cholesterol and $15.7 \%$ in LDL cholesterol. In a study evaluating the effect of L. plantarum PH04 on cholesterol, Nguyen et al., (2007) [71] administrated $4 \times 10^{8}$ $\mathrm{cfu} / \mathrm{ml}$ dose per mouse daily to twelve male hypercholesterolemic mice for 14 days and found reduction in total cholesterol and triglycerides (by 7 and $10 \%$, respectively) compared to control. Batish et al., (2010) [72] studied anti-hypercholesterolemic effects of $L$. plantarum LP91 $\left(>1.0 \times 10^{8} \mathrm{cfu} / \mathrm{g}\right)$ on SD rats for 3 weeks and revealed $23.26 \%, 21.09 \%$ and $38.13 \%$ reduction in total cholesterol, TAG and LDL cholesterol, respectively. $\mathrm{Hu}$ et al. (2013) [73] studied two NS lactobacillus strains, $L$. plantarum NS5 and L. delbrueckii NS12 for their cholesterol lowering effects on male SD rats fed a high cholesterol diet. In a recent study, Mohania et al. (2014) [74] showed antihypercholesterolemic effect of LaVK2 Dahi in 21 male Wistar rats with diet induced hypercholesterolemia, where plasma total cholesterol, LDL+VLDL and TAG levels found to be significantly decreased significantly at $22.6 \%, 89 \%$ and $64.2 \%$, respectively.

A variety of in vitro experiments and in vivo trials have provided experimental evidence to support the roles of probiotics in lowering serum cholesterol which subsequently leads to a reduced risk of hypertension [75]. Many of the proposed mechanisms and experimental evidence specifically targeting cholesterol lowering effects remain controversial. Thus, more properly designed in vivo trials may disclose additional understanding and knowledge to define the role of probiotics and their mechanism of action in this regard.

\section{Anticancer effects}

Probiotics, due to their ability to modulate the colonic microflora and encourage local and systematic immunity, could be one of the great interests to employ as therapeutics against various types of cancer by preventing the establishment, growth, and metastasis of transplantable and chemically induced tumors [76, 77]. An inverse relationship between the consumption of fermented dairy products, containing lactobacilli or bifidobacteria, and the incidence of cancer has been reported in epidemiological and population based casecontrol studies [78-80]. 
Short chain fatty acids (SCFA) produced by probiotic bacterial fermentation of indigestible polysaccharides and oligosaccharides have been shown to induce apoptosis of damaged cultured cells of colonic crypts [called aberrant crypts (AC), enlarged and elevated preneoplastic structures]. Butyrate also reduces the number of aberrant crypt foci in rats treated with the carcinogen azoxymethane [81]. Early laboratory studies using Lactobacillus $G G$ was found to reduce the incidence of induced tumors in an animal model of colon cancer [82]. Unlike standard chemotherapy agents, probiotic-derived agents target tumor cells without harming normal cells or causing immune suppression and other adverse side-effects [83, 84]. Aso \& colleagues (1992) [85] revealed the protective effect of $L$. casei Shirota on the recurrence of superficial bladder cancer in a randomized, controlled, multicentre study. After a year, tumor recurrence rate was significantly lower in subjects receiving L. casei $(57 \%)$ compared with the control group $(83 \%)$. Increases in the percentage of $\mathrm{T}$-helper (TH) cells and Natural Killer (NK) cells in adult colorectal cancer patients suggest that stimulation of the immune system by L. casei Shirota may have an important role in the suppression of tumor development [86]. Similar meta-analysis was performed by Bogdanov et al., (1975) [87] and Ayebo et al., (1981) [88]. Hosoda et al., (1996) [89] demonstrated that administration of $L$. acidophilus LA-22 showed remarkable decrease (71.9\%) in faecal mutagenicity.

Intake of LAB in fermented milk or other products influence gut flora enzymes, like $\beta$ glucuronidase, nitroreductase, and azoreductase as these enzymes convert procarcinogen to carcinogen [90]. A daily intake of $L$. acidophilus and $B$. bifidum for 3 weeks decreased the activity of nitroreductase but increased the activity of $\beta$ glucosidase [91]. This could be an advantage since $\beta$-glucosidase may release flavonoids which have antimutagenic, antioxidative and immune stimulatory effects $[92,83]$. Similar effects were observed by L. acidophilus NCFM and N-2 [82]. Other mechanisms by which probiotics may act as anti-tumorigenic factors are: enhancement of local and systemic immune response and produce molecules that neutralize or block mutagens; or these molecules may be directly antitumorigenic by nature [82]. The need for cautiously designed, long term studies in human is necessary in prevention of the earliest stages in the onset of evolution of cancer.

\section{Probiotics in prevention of allergic disease}

The prevalence of allergic diseases have increased considerably in recent decades, especially in countries with western lifestyle that characterized by high standard of hygiene, delivery mode, antibiotic use in the newborn and infant, and non-breast-milk diets, reduced exposure to microbes in daily environments, reduced consumption of fermented food [93-95]. Assessment of various strains of lactic acid bacteria can restore the normal intestinal permeability thereby improving intestinal processing of antigens ingested in the diet, reducing intestinal inflammation by producing IgE, potentiating of regulatory $\mathrm{T}$ cell cytokines, consequently reducing symptoms of atopic dermatitis [96].

Probiotics have been studied as possible dietary interventions to interrupt progression of eczema to rhinitis and rhinitis to asthma [97]. Moroi et al., (2011) [98] corroborated that, 22 to $24 \%$ reduction in the incidence of allergic dermatitis is due to the administration of strains of Lactobacillus in the first months of the child life, demonstrating the prevention capacity. In a randomized, double blind, placebo controlled study by Isolauri (1994) [99] investigated cow's milk sensitive infants with atopic dermatitis assessed their response to a hydrolyzed whey formula alone or in combination with LGG. At the end of one month the probiotic group had a significantly greater improvement in the extent and intensity of their eczema by decrease in the concentrations of fecal $\alpha$-trypsin and TNF- $\alpha$. The authors speculated that the LGG produced enzymes that can act as a suppressor of lymphocyte proliferation and also aided to generate protein breakdown products that result in IL-4 down regulation. Furthermore, the LGGstimulated increase in secretary $\operatorname{IgA}$ help in increased elimination of antigen and overall down regulation of hypersensitivity reactions. In 
a similar report, after 2 months, infants received whey formula with probiotic LGG showed significant improvement in extent and severity of atopic eczema by reducing the concentrations of soluble CD4 in serum and eosinophilic protein $\mathrm{X}$ in urine [100]. These findings have also been recently confirmed by Rosenfeldt et al., (2003) [101], in which 56 percent of patients experienced improvement in eczema by having diet containing L. rhamnosus and L. reuteri compared to $15 \%$ in placebo group. Similar outcomes were observed for L. rhamnosus $G G$ [102] and L. fermentum [103]. Some studies have also shown that $80 \%$ of the patients with acne that used probiotics had a reduction in acne inflammation [104, 105].

\section{Probiotics in Respiratory diseases}

Recently probiotics have being exploited in the prophylaxis of different respiratory tract ailments such as sinusitis, rhino sinusitis, pharyngitis, otitis. The strains of Lactobacillus plantarum \& L. casei, L. fermentum VRI-003, Bifidobacterium breve 99, B.longum SP 07/3 among others were used in a combined or single action of respiratory infections viewing satisfactory results the drop of acute episodes of the diseases mentioned above as well as a reduction in the duration of the episode in chronic diseases [106, 107].

Latest study evaluated the use of Lactobacillus in patients with cystic fibrosis that are chronically colonized by Pseudomonas aeruginosa [108]. Some probiotic strains such as Lactobacillus plantarum and Lactobacillus rhamnosus aids in prophylaxis and can avert nosocomial pneumonias characterized as respiratory tract colonization by pathogenic bacteria, chiefly Pseudomonas aeruginosa [109]. Further studies are needed to better explain the probiotics action and mechanism for treatment [110].

\section{Probiotics in Urogenital diseases}

Bacterial vaginosis is one of the most common infectious disorders affecting women. Lactobacilli are major constituents of the normal vaginal flora. Their production of bacteriocins, lactic acid, and hydrogen peroxide are mechanisms which keep pathogenic colonies of several anaerobic floras, including Gardnerella vaginalis, Bacteroides sp., $\beta$ - Streptococci and Mobiluncus/Falcivibrio sp. from proliferating $[111,112]$.

There is a developing role for the use of probiotics (both oral and vaginal suppositories) in the genitourinary (GU) system, especially for vaginitis, whether from bacterial or fungal etiology. Reid et al., (2003) [113] showed consumption of yogurt containing L. acidophilus decreased the incidence of Candida yeast infections. In one open clinical trial, 40 female patients restore the physiological $\mathrm{pH}$ of vagina by controlling symptoms of bacterial vaginosis after the treatment with L. rhamnosus [114]. In another randomized, double blind placebo controlled study in ninety women after treatment of Candidiasis and Vaginosis with probiotic $L$. gasseri, L. casei, L. fermentum, P. acidilactici, results showed delay in recurrence of symptoms of vaginosis with prevention in vaginal colonization by pathogens [115]. In a parallel study by (Ya et al., 2010) [116], L. rhamnosus, $L$. acidophilus, S. thermophilus showed reduction in frequency of bacterial vaginosis in 120 women.

\section{Additional health benefits of Probiotics}

\subsection{Assisting Vitamin and Mineral Uptake}

Probiotics increase the bioavailability of vitamins and protein in the GI tract as a result of increased acidification of the gut $\mathrm{pH}$ by the production of lactic acid. Compared to milk, yogurt results in better absorption of such vitamins and minerals as calcium, copper, iron, manganese, phosphorous and zinc [117].

\subsection{Pregnancy}

Vaginal application of highly adhesive Lactobacilli to 30 pregnant women with dysbacteriosis of the birth canal resulted in correction of bacterial ecology of vagina and intestine [118] with favorably influence the course of pregnancy, labor, and the postpartum period [119]. 


\subsection{Oral health}

Lactobacilli have the ability to inhibit the growth of periodontopathogens including, P. gingivalis, P. intermedia and A. actinomycetemcomitans [120,121]. Comelli and colleagues investigated the 23 bacterial strains used in the dairy industry, among them Streptococcus thermophilus and Lactobacillus lactis ssp. lactis were the only ones with the ability to form biofilms present on a hydroxyapatite surface and to interfere with development of the cariogenic species Streptococcus sobrinus [122]. This concept prompts a new horizon on the relationship between diet and oral health.

\subsection{Obesity}

Obesity is a growing problem in the population and affects all age groups. There are several studies that make a direct relationship between abdominal fat deposition and the imbalance of the gut microbiota [123, 124]. Therapeutic efforts indicate that probiotics help in maintaining the balance of intestinal microflora and recommended for the treatment of obesity-related disorders following the nutritional and pharmacological treatments $[125,126]$.

\subsection{AIDS}

HIV infection can upset the natural balance of healthy bacteria in the intestine, which can be restored by adding probiotics in diet. Many evidences available that shows the probiotics help in re-establishment of CD4 ( $\mathrm{T}$ helper cells) counts so that the immune system is more prepared to battle against HIV linked infections [127].

\subsection{Hypertension}

High levels of blood cholesterol, diabetes, and improper modulation of rennin, imbalanced sexual hormones, and obesity are risk factors causing hypertension [128]. Studies suggest that consumption of certain lactobacilli (specially L. helveticus), or their formulation, may reduce serum cholesterol and improve lipid profiles, subsequently attenuating the risk of hypertension [129-131].

\section{Conclusion and outlook}

Probiogenomic, Nutrigenomics and Metabolomics are rapidly developing new bodies of knowledge that will change future research and practice in human nutrition. Probiotics have been shown to promote a variety of biological effects in a number of physiological conditions and pathologies, including allergy, intestinal and liver diseases, urinary and upper respiratory infections, AIDS and metabolic diseases. These effects are strain specific and primarily mediated through changes in the faecal microbiota and immune modulation. In addition, multi-centered and replicate studies are necessary to evaluate the actual role of probiotics in the amelioration of symptoms for many diseases. Most of the clinical studies are still targeted to general health benefits or especially on gastrointestinal tract disorders. In coming years, India will have more systematic multicenter clinical trials on foreign as well as indigenous probiotic strains to combat diseases.

\section{References}

1. Holzapfel WH, Hebrer P, Snel J. Overview of gut flora and probiotics. International Journal of Food Microbiology 1998; 41: 85-101. PMID: 9704859

2. Hooper LV, Gordon JI. Commensal host-bacterial relationships in the gut. Science 2001; 292: 1115-18.

3. Gruaner F, Malagelada JR. Gut flora in health and disease. Lancet 2002; 360: 512-19. PMID: 12401268.

4. Grover S, Rashmi HM, Shrivastava AK., Batish VK. Probiotics for human healthnew innovations and emerging trends. Gut Pathogens 2012; 4: 15-29. doi: 10.1186/1757-4749-4-15.

5. FAO/WHO, 2002. Guidelines for the evaluation of probiotics in food. http://www.who.int/foodsafety/fs_mana gement/en/probiotic_guidelines.pdf.Aug ust 2014. 
6. Sartor RB. Therapeutic manipulation of the enteric microflora in Inflammatory Bowel Diseases: Antibiotics, Probiotics, and Prebiotics. Gastroenterology 2004; 126: 1620-1633. DOI: 10.1053/j.gastro.2004.03.024

7. Sudha MR, Chauhan P, Dixit K, Babu S, Jamil K. Probiotics as complementary therapy for hypercholesterolemia. Biology and Medicine 2009; 1(4): 1-13.

8. Scaldaferri F, Viviana G, Loris RL, Fabio DZ, Francesca M, Ivo B, Giovanni B, Valentina P, Lucrezia L, Giovanni C, Eleonora G, Alessandro S, Antonio G. Gut microbial flora, prebiotics and probiotics in IBD: Their current usage and utility. BioMed Research International 2013; 13: 1-10.

9. Hirayama K, Rafter J. Probiotics in Cancer Prevention. In Probiotics in Food Safety and Human Health, Ipek G., Vijay, K.J. and Mohamed, A. (Eds). CRC press London 2006; pp. 365-376.

10. Jain S, Yadav M, Menon S, Yadav H, Marotta F. Anticarcinogenic effects of probiotics, prebiotics, and synbiotics. In hand book of prebiotics and probiotics ingredients health benefits and food applications, Sungsoo, S.C. and Terry, F.E. (Eds). CRC press, London. 2010; pp. 273-292.

11. Prajapati JB \& Shah NP. Probiotics and Health claims- An Indian Perspective, In: 'Probiotics and Health Claims', First edition, (Eds.) Wolfgang Kneifel and Seppo Salminen, Blackwell Publishing Limited, Oxford, U.K. 2011; pp. 134148.

12. Grower S, Prajapati JB, Aprana SV, Rashmi HM, Batish VK. Probiotic research and product development carried out in India from national perspective. A status paper published by Probiotic Association of India, Karnal 2014; pp. 1-106.

13. WHO, 2013. Ending preventable deaths from pneumonia and diarrhoea by 2025 , integrated global action plan for the prevention and control of pneumonia and diarrhoea (GAPPD). 12 April 2013.

14. Amdekar S, Singh V. Probiotics: For Stomach Disorders - An Evidence Based Review. American Journal of Pharmatech and Research 2012; 2(2): 124.

15. Parvez S, Malik KA, Kang SA, Kim HY. Probiotics and their fermented food products are beneficial for health. Journal of Applied Microbiology 2006; 6(100): 1171-1185. DOI: 10.1111/j.1365-2672.2006.02963.x

16. Lemberg DA, Ooi CY, Day AS. Probiotics in paediatric gastrointestinal diseases. Journal of Paediatrics and Child Health 2007; 43: 331-336. DOI: 10.1111/j.1440-1754.2007.01076.x

17. Yan F, Cao H, Cover TL, Whitehead R, Washington MK, Polk DB. Soluble proteins produced by probiotic bacteria regulate intestinal epithelial cell survival and growth. Gastroenterology 2007, 132(2): 562-575.PMID: 17258729.

18. Szajewska H, Setty M, Mrukowicz J, Guandalini S. Probiotics in gastrointestinal diseases in children: Hard and not-so-hard evidence of efficacy. Journal of Pediatric Gastroenterology and Nutrition 2006; 42(5): 454- 475.4 doi: 10.1097/01.mpg.0000221913.88511.72

19. McFarland LV. Evidence-based review of probiotics for antibiotic-associated diarrhea and Clostridium difficile infections. Anaerobe 2009; 15(6): 274280.

doi:

10.1016/j.anaerobe.2009.09.002.

20. Sazawal S, Hiremath G, Dhingra U, Malik P, Deb S, Black RE. Efficacy of probiotics in prevention of acute diarrhoea: a meta-analysis of masked, randomized, placebo-controlled trials. The Lancet Infectious Diseases 2006; 6: 374-382. PMID: 16728323.

21. Vrese M \& Marteau PR. Probiotic and prebiotic: Effect on diarrhea. Journal of Nutrition 2007; 137(3 Suppl 2): 803811. 
22. Kotowska M, Albrecht P, Szajewska H. Saccharomyces boulardii in the prevention of antibiotic-associated diarrhoea in children: a randomized double-blind placebo-controlled trial. Alimentary Pharmacology \& Therapeutics 2005; 21: 583-590. DOI: $\underline{10.1111 / j .1365-2036.2005 .02356 . x}$

23. Cremonini F, Di Caro S, Nista EC. Meta-analysis: the effect of probiotic administration on antibiotic-associated diarrhoea. Pharmacology \& Therapeutics 2002; 16: 1461-1467.

24. Singhi SC\& Baranwal A. Probiotic use in the critically ill. Indian Journal of Pediatrics 2008; 75(6), 621-627.

25. Borody TJ, Warren EF, Leis S. Treatment of ulcerative colitis using fecal bacteriotherapy. Journal of Clinical Gastroenterology 2003; 37: 4247. PMID: 12811208

26. Shah NP. Functional cultures and health benefits. International Dairy Journal 2007; 17: 1262-1277.

27. Sur D, Manna B, Niyogi SK, Ramamurthy T, Patil A, Nomoto K, Takahashi T, Shima T, Tsuji H, Kurakawa T, Takeda Y, Nair GB, and Bhattacharya SK. Role of probiotics in preventing acute diarrhea in children: A community based, randomized, double blind placebo controlled field trial in an urban slum. Epidemiology \& Infection 2011; 139: 919-926. DOI: 10.1017/S0950268810001780

28. Basu S, Paul DK, Ganguly S, Chatterjee M, Chandra PK. Efficacy of high-dose Lactobacillus rhamnosus GG in controlling acute watery diarrhea in Indian children: a randomized controlled trial. Journal of Clinical Gastroenterology 2009; 43: 208-213. doi: 10.1097/MCG.0b013e31815a5780

29. Dubey AP, Rajeshwari K, Chakravarty A, Famularo G. Use of VSL\#3 in the treatment of rotavirus diarrhea in children: preliminary results. Journal of Clinical Gastroenterology 2008; 42(3):
126-129. doi:

10.1097/MCG.0b013e31816fc2f6.

30. Nomoto K. Prevention of infection by probiotics. Journal of Bioscience \& Bioengineering 2005; 100: 583-592.

31. Sgouras D, Maragkoudakis P, Petraki K. In vitro and in vivo inhibition of Helicobacter pylori by Lactobacillus casei strain Shirota. Applied Environmental Microbiology 2004; 70: 518-526. doi: 10.1128/AEM.70.1.518$\underline{526.2004}$

32. Filippo C, Filippo C, Di Caro S, Santarelli L, Armuzzi A, Gasbarrini G, Gasbarrini A, 2001. Helicobacter pylori treatment: a role for Probiotics. Journal of Digestive Diseases 2001; 19: 144147.

33. Prasanthi $\mathrm{CH}$; Prasanthi NL; Manikiran SS; Rao NR. Focus on current trends in the treatment of Helicobacter pylori infection: An update. International Journal of Pharmaceutical Sciences Review and Research 2011; 9(1): 42-51.

34. Patel A, Shah N, Prajapati JB. Clinical appliance of probiotics in the treatment of Helicobactor pylori infection - A brief review. Journal of Microbiology, Immunology and Infection 2014; 47: 429-437.doi: 10.1016/j.jmii.2013.03.010

35. Aiba Y, Suzuki N, Kabir AM, Takagi A, Koga Y. Lactic acid-mediated suppression of Helicobacter pylori by the oral administration of Lactobacillus salivarius as a Probiotic in a gnotobiotic murine model. American Journal of Gastroenterology 1998; 93: 2097-2101.

36. Michetti P, Dorta G, Wiesel PH, Brassart D, Verdu E, Herranz M, Felley C, Porta N, Rouvet M, Blum AL, Corthésy-Theulaz I. Effect of whey based culture supernatant of Lactobacillus acidophilus johnsonii La1 on Helicobacter pylori infection in humans. Digestion 1999; 60: 203-209. PMID: 10343133

37. Cruchet S, Obregon MC, Salazar G, Diaz E, Gotteland M. Effect of ingestion of a dietary product containing 
Lactobacillus johnsonii La1 on Helicobacter pylori colonization in children. Nutrition 2003; 19: 716-721. PMID: 12921879

38. Cats A, Kuijpers EJ, Bosschaert MAR, Pot RGJ, Vandenbroucke-Grauls CMJE, Kusters JG. Effect of fermented consumption of a Lactobacillus caseicontaining milk drink in Helicobacter pylori-colonized subjects. Alimentary Pharmacology \& Therapeutics 2003; 17: 429-435. PMID: 12562457

39. Wang KY, Li SN, Liu CS, Perng DS, Su YC, Wu DC, Jan CM, Lai CH, Wang TN, Wang WM. Effects of ingesting Lactobacillus and Bifidobacterumcontaining yogurt in subjects with colonized Helicobacter pylori. American Journal of Clinical Nutrition 2004; 80, 737-741. PMID:15321816

40. Datta S, Chattopadhyay S, Patra R. Most Helicobacter pylori strains of Kolkata in India are resistant to metronidazol but susceptible to other drugs commonly used for eradication and ulcer therapy. Alimentary Pharmacology \& Therapeutics 2005; 22(1): 51-57.

41. Devi SM, Ahmed I, Francalacci P. Ancestral European roots of Helicobacter pylori in India. BMC Genomics 2007; 8: 184-195. DOI: 10.1186/1471-2164-8-184

42. Chaturveddi R, Asim M, Hoge S, Lewis ND, Singh K. Polyamines impair immunity to Helicobactor pylori by inhibiting L-arginine uptake required for nitric oxide production. Gastroenterology 2010; 139: 1686-1698. doi: 10.1053/j.gastro.2010.06.060.

43. Esteve E, Ricart W, Fernández R, Jose M. Gut microbiota interactions with obesity, insulin resistance and type 2 diabetes: did gut microbiota co-evolve with insulin resistance? Current Opinion in Clinical Nutrition and Metabolic Care 2011; 14(5): 483-490. doi: 10.1097/MCO.0b013e328348c06d.

44. Kootte RS, Vrieze A, Holleman F, Dallinga- Thie GM, Zoetendal EG,
deVos WM. The therapeutic potential of manipulating gut microbiota in obesity and type 2 diabetes mellitus. Diabetes Obesity and Metabolism 2012; 14: $112-120$. doi: $10.1111 /$ j.14631326.2011.01483.x.

45. Panwar H, Rashmi HM, Batish VK, Grover S. Probiotics as potential biotherapeutics in the management of type 2 diabetes prospects and perspectives. Diabetes/Metabolism Research and Reviews 2013; 29(2): 103112.

46. Calcinaro F, Dionisi S, Marinaro M, Candeloro P, Bonato V, Marzotti S, Corneli RB, Ferretti E, Gulino A, Grasso F, De Simone C, Di Mario U, Falorni A, Boirivant M, Dotta F. Oral probiotic administration induces interleukin-10 production and prevents spontaneous autoimmune diabetes in the nonobese diabetic mouse Diabetologia 2005; 48: 1565-1575. PMID: 15986236

47. Yadav H, Jain S, Sinha PR. Antidiabetic effect of probiotic dahi containing Lactobacillus acidophilus and Lactobacillus casei in high fructose fed rats. Nutrition 2007; 23(1): 62-68.

48. Ejtahed HS, Mohtadi-Nia J, HomayouniRad A, Niafar M, Asghari-Jafarabadi M, Mofid V, Akbarian-Moghari A. Effect of probiotic yogurt containing Lactobacillus acidophilus and Bifidobacterium lactis on lipid profile in individuals with type 2 diabetes mellitus. Journal of Dairy Science 2011; 94(7): 3288-3294. doi: 10.3168/jds.2010-4128.

49. de Vrese M, Stegelmann A, Richter B, Fenselau S, Laue C. Probioticscompensation for lactase insufficiency. American Journal of Clinical Nutrition 2001; 73: 421-429.

50. Bulhões AC, Goldani HA, Oliveira FS, Matte US, Mazzuca RB. Correlation between lactose absorption and the $\mathrm{C} / \mathrm{T}$ 13910 and G/A-22018 mutations of the lactase-phlorizin hydrolase (LCT) gene in adult-type hypolactasia. Brazilian Journal of Medical and Biological 
Research 2007; 40: 1441-1446. PMID: 17934640

51. Savaiano DA, AbouElAnouar A, Smith DE, Levitt MD. Lactose mal-absorption from yogurt, pasteurized yogurt, sweet acidophilus milk, and cultured milk in lactase-deficient individuals. American Journal of Clinical Nutrition 1984; 40: 1219-1223.

52. Montes RG1, Bayless TM, Saavedra JM, Perman JA. Effect of milk inoculated with Lactobacillus acidophilus or a yogurt starter culture in lactosemaldigesting children. Journal of Dairy Science 1995; 78: 1657-1664. PMID: 8786651

53. Alm L. Effect of fermentation on lactose, glucose, and galactose content in milk and suitability of fermented milk products for lactose intolerant individuals. Journal of Dairy Science 1982; 65: 346-352.

54. Levri KM, Ketvertis K, Deramo M, Merenstein JH, D'Amico F. Do probiotics reduce adult lactose intolerance? A systematic review. The Journal of Family Practice 2005; 54: 613-620. PMID: 16009090

55. He T, Priebe MG, Zhong Y, Huang C, Harmsen HJ. Effects of yogurt and bifidobacteria supplementation on the colonic microbiota in lactose-intolerant subjects. Journal of Applied Microbiology 2008; 104: 595-604. PMID: 17927751

56. Marteau P, Sokol H, Dray X, Seksik P. Bacteriotherapy for inflammatory bowel disease: therapeutic tool and/or pharmacological vectors? Gastroenterologie Clinique Biologique. 2009; 33(3): 228-234.

57. Fujimori S, Tatsuguchi A, Gudis K, Kishida T, Mitsui K, Ehara A, Kobayashi T, Sekita Y, Seo T, Sakamoto C. High dose probiotic and prebiotic cotherapy for remission induction of active Crohn $\mathrm{s}$ disease. Journal of Gastroenterology and Hepatology 2007; 22: 1199-1204.
58. Furrie E, Macfarlane S, Kennedy A, Cummings JH, Walsh SV, Macfarlane GT. Synbiotic therapy (Bifidobacterium longum /Synergy 1) initiates resolution of inflammation in patients with active ulcerative colitis: A randomized controlled pilot trial. Gut 2005; 54: 242249. doi: 10.1136/gut.2004.044834

59. Rembacken BJ, Snelling AM, Hawkey PM. Non-pathogenic Escherichia coli versus mesalazine for the treatment of ulcerative colitis: a randomised trial. Lancet. 1999; 354: 635-639.

60. Kruis W, Fric P, Pokrotnieks J. Maintaining remission of ulcerative colitis with the probiotic Escherichia coli Nissle 1917 is as effective as with standard mesalazine. Gut. 2004; 53:1617-1623.

doi:10.1136/gut.2003.037747

61. Mimura T, Rizzello F, Helwig U. Once daily high dose probiotic therapy (VSL\#3) for maintaining remission in recurrent or refractory pouchitis. Gut. 2004; 53: 108-114. PMID: 14684584

62. Welters CFM, Heineman E, Thunnissen FBJM, Van den Bogaard AEJM, Soeters PB, Baeten C. GMI. Effect of dietary inulin supplementation on inflammation of pouch mucosa in patients with an ileal pouch-anal anastomosis. Diseases of the Colon and Rectum 2002; 45(5): 621627.

63. Pronio A, Montesani C, Butteroni C. Probiotic administration in patients with ileal pouch-anal anastomosis for ulcerative colitis is associated with expansion of mucosal regulatory cells. Inflammatory Bowel Diseases 2008; 14: 662-668.

64. Bibiloni R, Fedorak RN, Tannock GW. VSL\#3 probiotic-mixture induces remission in patients with active ulcerative colitis. American Journal of Gastroenterology 2005; 100: 1539-1546. PMID: 15984978

65. Ashar MN \& Prajapati JB. Serum cholesterol level in humans fed with 
acidophilus milk. Indian Journal of Microbiology 2001; 41: 257-263.

66. Mann GV \& Spoerry A. Studies of a surfactant and cholesterolemia in the Masai. American Journal of Clinical Nutrition 1974; 27(5): 464-469.

67. Klaver FAM \& Van Der Meer R. The assumed assimilation of cholesterol by Lactobacilli and Bifidobacterium bifidum is due to their bile saltdeconjugating activity. Applied and Environmental Microbiology 1993; 59: 1120-1124.

68. DeSmet I, Van Hoorde L, De Saeyer N, Van de Woestyne M, Verstraete W. In vitro study of bile salt hydrolase $(\mathrm{BSH})$ activity of $\mathrm{BSH}$ isogenic Lactobacillus plantarum 80 strains and estimation of cholesterol lowering through enhanced BSH activity. Microbial Ecology in Health and Disease 1994; 7: 315-329.

69. Tahri K, Grill JP, Schneider F. Bifidobacteria strain behavior toward cholesterol: Co precipitation with bile salts and assimilation Current Microbiology 1996; 33: 187-193. PMID: 8672088

70. Fukushima $M$ \& Nakano M. Effects of a mixture of organisms, Lactobacillus acidophilus or Streptococcus faecalis on cholesterol metabolism in rats fed on a fat- and cholesterol-enriched diet. British Journal of Nutrition 1996; 76: 857-867.

71. Nguyen TDT, Kang JH, Lee MS. Characterization of Lactobacillus plantarum $\mathrm{PH} 04$, a potential probiotic bacterium with cholesterol-lowering effects. International Journal of Food Microbiology 2007; 113: 358- 361. PMID: 17140690

72. Batish VK, Grover S, Kumar R. Hypocholesterolemic effect of dietary inclusion of two putative probiotic bile salt hydrolase- producing Lactobacillus plantarum strains in Sprague-Dawley rats. British Journal of Clinical Nutrition 2010; 105(4): 561-573.

73. Hu X, Wang T, Li W, Jin F, Wang L. Effects of NS Lactobacillus strains on lipid metabolism of rats fed a highcholesterol diet. Lipids in Health \& Diseases 2013; 12, 67-79. doi: 10.1186/1476-511X-12-67.

74. Mohania D, Kansal VK, Sagwal R, Kruzliak P. Probiotic LaVK2 dahi improves lipid profiles in hypercholesterolemic rats. Advances in Dairy Research 2014; 2: 1-7.

75. Liong MT, Shah NP. Acid and bile tolerance and cholesterol removal ability of lactobacilli strains. Journal of Dairy Science 2005; 88: 55-66. PMID: 15591367

76. Gill HS \& Cross ML. Probiotics and immune function. In: Calder PC, Field CJ, Gill HS, (Eds). Nutrition and immunity. Wallingford, UK: CABI International, 2001; pp. 251-72. doi: 10.1136/pgmj.2003.008664

77. Rafter J. Lactic acid bacteria and cancer. British Journal of Nutrition 2002; 88(suppl 3): 89-94.

78. Goldin BR \& Gorbach SL. The effect of L. acidophilus feeding on human intestinal bacterial enzymes activity. American Journal of Clinical Nutrition 1984; 39: 756-761.

79. Fernandes CF, Shahani KM, Standinger W, Amer MA. Anticarcinogenic properties of lactobacilli as modulated by immune factors. Brief Communication of the $23^{\text {rd }}$ International Dairy Congress, Montreal 1990; Oct. 812, Belgium. 1, p. 178.

80. Patidar SK \& Prajapati JB. Methods for assessing the immunostimulating properties of dietary lactobacilli- a critical appraisal. Journal of Food Science \&Technology 2003; 34(3): 181194.

81. Capusro G, Marignani M \& Delle Fave G. Probiotics and the incident of colorectal cancer: when evidence is not evident. Digestive and liver disease 2006; 38: 277-282.

82. Geier DA \& Geier MR. Prospective study of mercury toxicity in biomarkers in Autistic spectrum disorders. Journal 
of Toxicity and Environmental Health 2007; 70(20): 1723-1730. DOI: $\underline{10.1080 / 15287390701457712}$

83. Rolfe RD. The role of probiotic cultures in the control of gastrointestinal health. Journal of. Nutrition 2000; 130: 396402. PMID: 10721914

84. Zhu Y, Michelle Luo T, Jobin C. Gut microbiota and probiotics in colon tumorigenesis. Cancer Letters 2011; 309: 119-127. doi: 10.1016/j.canlet.2011.06.004.

85. Aso Y, Akaza H, Kotake T. Prophylactic effect of a Lactobacillus casei preparation on the recurrence of superficial bladder cancer. Urologia Internationalis 1992; 49: 125-129.

86. Sawamura A, Yamaguchi $\mathrm{Y}$, Toge $\mathrm{T}$. Enhancement of immuno-activities by oral administration of Lactobacillus casei in colorectal cancer patients. Biotherapy 1994; 8: 1567-1572.

87. Bogdanov IG, Dalev PG, Gurevich AI, Kowshv MN, Malkova VP. Antitumor glycopeptides from the cell wall of $L$. bulagaricus. Bulletin of Experimental Biology and Medicine 1975; 84: 17501753.

88. Ayebo AD, Shahani KM, Dam R. Antitumor component(s) of yogurt fractionation. Journal of Dairy Science 1981; 64: 2318-2323. DOI: 10.3168/jds.S0022-0302(81)82853-6

89. Hosoda M, Ashimoto R, He F, Morita $\mathrm{H}$, Hosono A. Effect of administration of milk fermented with L. acidophilus LA2 on fecal mutagenicity and microflora in the human intestine. Journal of Dairy Science 1996; 79: 745-749.

90. Wollowski I, Rechkemmer G, PoolZobel BL. Protective role of probiotics and prebiotics in colon cancer. American Journal of Clinical Nutrition 2001; 73; 451-455. DOI: $10.1155 / 2010 / 214186$

91. Marteau P, Rochart P, Flourie B, Pellier $\mathrm{P}$, Santos L, Desjeux JF Rambaud JC. Effect of chronic ingestion of a fermented dairy product containing Lactobacillus acidophilus and
Bifidobacterium bifidum on metabolic activities of the colonic flora in humans. American Journal of Clinical Nutrition 1990; 52: 685-688. PMID: 2119557

92. Stoner GD \& Mukhtar H. Polyphenols as cancer chemopreventive agents. Journal of Cellular Biochemistry 1995; 22: 169-180. PMID: 8538195

93. Bjorksten B, Sepp E, Julge K. Allergy development and the intestinal microflora during the first year of life. Journal of Allergy and Clinical Immunology 2001; 108: 516-20.

94. Spergel JM \& Paller AS. Atopic dermatitis and the atopic march. Journal of Allergy and Clinical Immunology 2003; 112: 118-127.

95. Weinmayr G, Weiland SK, Björkstén B, Brunekreef B, Büchele G, Cookson WO, Marcos GL, Gotua M, Gratziou C, Hage MV, Mutius EV, Riikjärv MA, Rzehak P, Renato T, Stein R.T, Strachan DP, Tsanakas J, Wickens K, Wong GW. Atopic sensitizationand the international variation of asthma symptom prevalence in children. American Journal of Respiratory and Critical Care Medicine 2007; 176: 565-574.

96. Ji GE. Probiotics in primary prevention of atopic dermatitis. Forum of Nutrition 2009; 61: 117-128.

97. Shane AL, Cabana MD, Vidry S. Guide to designing, conducting, publishing and communicating results of clinical studies involving probiotic applications in human participants. Gut Microbes 2010; 1: 243-253. PMID: 21727031

98. Moroi M, Uchi S, Nakamura K, Sato S, Shimizu N. Beneficial effect of a diet containing heat-killed Lactobacillus paracasei K71 on adult type atopic dermatitis. Journal of Dermatology 2011; 38: 131-139.

99. Isolauri E, Kaila M, Mykkanen H, Ling WH, Salminen S. Oral bacteriotherapy for viral gastroenteritis. Digestive Diseases and Sciences 1994; 39: 25952600. PMID: 7995184 
100. Isolauri E, Arvola T, Sutas Y, Moilanen E, Salminen S. Probiotics in the management of atopic eczema. Clinical and Experimental Allergy 2000; 30: 1604-1610. PMID: 11069570

101. Rosenfeldt V, Bemfeldt E, Vielsen S, Michaelsen K, Jeppesen D, Valerius NH, Paerregaard A. Effect of probiotic Lactobacillus strains in children with atopic dermatitis. The Journal of Allergy and Clinical Immunology 2003; 111: 389-395.

102. Pohjavouri E, Viljanen M, Korpela R, Kuitunen M, Tiittanen M, Vaarala O, Savilahti E. Lactobacillus GG effect in increasing IFN- $\gamma$ production in infants with cow's milk allergy. The Journal of Allergy and Clinical Immunology 2004; 114: 131-136.

103. Prescott SL, Dunstan JA, Hale J, Breckler L, Lehmann H, Weston S. \& Richmond P. 2005. Clinical effects of probiotics are associated with increased IFN- $\gamma$ responses in very young children with atopic dermatitis. Clinical and Experimental Allergy 2005; 35: 15571564. PMID: 16393321

104. Muizzuddin N, Maher W, Sullivan M, Schnittger S, Mammone $T$. Physiological effect of a probiotic on skin. Journal of Cosmetic Science 2012; 63: 385-395. PMID: 23286870

105. Jung GW, Tse JE, Guiha I, Rao J. Prospective, randomized, open label trial comparing the safety, efficacy, and tolerability of an acne treatment regimen with and without a probiotic supplement and aminocycline in subjects with mild to moderate acne. Journal of Cutaneous Medicine and Surgery 2013; 17: 114122.

106. Hao Q, Lu Z, Dong BR, Huang CQ, Wu T. Probiotics for preventing acute upper respiratory tract infections. Cochrane Database of Systemic Review 2015; Issue 2. Art no. CD006895. doi: 10.1002/14651858.CD006895.pub2.

107. Popova M, Molimard P, Courau S, Crociani J, Dufour C. Beneficial effects of probiotics in upper respiratory tract infections and their mechanical actions to antagonize pathogens. Journal of Applied Microbiology 2012; 113: 13051318.

108. Wolvers D, Antoine JM, Myllyluoma E, Schrezenmeir J, Szajewska H. Guidance for substantiating the evidence for beneficial effects of probiotics: prevention and management of infections by probiotics. Journal of Nutrition 2010; 140: 698-712.

109. Morrow LE, Kollef MH. Recognition and prevention of nosocomial pneumonia in the intensive care unit and infection control in mechanical ventilation. Critical Care Medicine 2010; 38: 352-362.

110. Knight DJ, Gardiner D, Banks A, Snape SE, Weston VC. Effect of symbiotic therapy on the incidence of ventilator associated pneumonia in critically ill patients: a randomised, double-blind, placebo-controlled trial. Intensive care Medicine 2009; 35: 854-861.

111. Larsen B. Vaginal flora in health and disease. Clinical Obstetrics and Gynecology 1993; 36: 107-121.

112. Jones K, Ewigman B, Stevermer J. Help for recurrent bacterial vaginosis. The Journal of Family Practice 2011; 60(2): 91-93.

113. Reid G, Bruce AW. Urogenital infections in women: Can probiotics help? Postgraduate Medical Journal 2003; 79(934): 428-432. doi: $10.1136 / \mathrm{pmj} .79 .934 .428$

114. Rossi A, Rossi T, Bertini M, Caccia, G. The use of Lactobacillus rhamnosus in the therapy of bacterial vaginosis. Evaluation of clinical efficacy in a population of 40 women treated for 24 months. Archives of Gynecology and Obstetrics 2010; 281: 1065-1069.

115. Ehrström S, Daroczy K, Rylander E, Samuelsson C, Johannesson U, Anzén B, Påhlson C. Lactic acid bacteria colonization and clinical outcome after probiotic supplementation in 
conventionally treated bacterial vaginosis and vulvovaginal candidiasis. Microbes and Infection 2010; 12: 691699. doi:10.1016/j.micinf.2010.04.010

116. Ya W, Reifer C, Miller LE. Efficacy of vaginal probiotic capsules for recurrent bacterial vaginosis: a double-blind, randomized, placebo-controlled study. American Journal of Obstetrics and Gynecology 2010; 203: 121-126.

117. Sanders ME, Klaenhammer TR. Invited review: the scientific basis of Lactobacillus acidophilus NCFM functionality as a probiotic. Journal of Dairy Sciences 2001; 84: 319-331. DOI: 10.3168/jds.S0022-0302(01)74481-5

118. Korshunov VM, Kafarskaia LI, Volodin NN, Tarabrina NP. The correction of dysbiotic disorders of the vaginal microflora by using a preparation made from highly adhesive lactobacteria. Zhurnal Mikrobiologii, Epidemiologii, Immunobiologii 1990; 7: 17-19.

119. Litiaeva LA. The effect of a combination of immune and bacterial preparations on microbial ecology of pregnant women in a risk group. Akush Ginekol (Sofilia) 1993; 1: 19-22.

120. Riccia DN, Bizzini F, Perilli MG, Polimeni A, Trinchieri V, Amicosante G. Anti-inflammatory effects of Lactobacillus brevis (CD2) on periodontal disease. Oral Diseases 2007; 13: 376-385. PMID: 17577323

121. Victor DJ, Delton TehChai Liu, Anupama T, Deva Priya AM. Role of probiotics and bacterial replacement therapy in periodontal disease management. SRM University Journal of Dental Science. 2010; 1(1): 99-102.

122. Selwitz RH, Ismail AI, Pitts NB. Dental caries. Lancet 2007; 69: 51-59. PMID: 17208642

123. An HM, Park SY, Lee do K, Kim JR, Cha MK. Anti-obesity and lipidlowering effects of Bifidobacterium spp. in high fat diet-induced obese rats. Lipids in Health Disease 2011; 11: 110: 116.
124. Lee SJ, Bose S, Seo JG, Chung WS, Lim CY. The effects of coadministration of probiotics with herbal medicine on obesity, metabolic endotoxemia and dysbiosis: A randomized double-blind controlled clinical trial. Clinical Nutrition 2013; 33: 973-981. doi: 10.1016/j.clnu.2013.12.006.

125. Cani PD, Bibiloni R, Knauf C, Waget A, Neyrinck AM. Changes in gut microbiota control metabolic endotoxemia-induced inflammation in high-fat diet-induced obesity and diabetes in mice. Diabetes 2008; 57: 1470-1481. doi: $10.2337 / \mathrm{db} 07-1403$

126. Kotzampassi K, Giamarellos-Bourboulis EJ, Stavrou G. Obesity as a consequence of gut bacteria and diet interactions. ISRN Obesity 2014; Article ID: 651895.

127. Gregor R. The potential role for probiotic yogurt for people living with HIV/AIDS. Gut Microbes 2010; 1: 411-414.

128. Yekeen LA, Sanusi RA, Ketiku AO. Prevalence of obesity and high level of cholesterol in hypertension: Analysis of data from the university college hospital. African Journal of Biomedical Research 2003; 6(3): 129-132.

129. Seppo L, Jauhiainen T, Poussa T, Korpela R. Fermented milk high in bioactive peptides has a blood pressurelowering effect in hypertensive subjects. American Journal of Clinical Nutrition 2003; 77: 326-330.PMID: 12540190

130. Aihara K, Kajimoto O, Hirata $H$, Takahashi R, Nakamura Y. Effect of powdered fermented milk with Lactobacillus helveticus on subjects with high-normal blood pressure or mild hypertension. The Journal of American College of Nutrition 2005; 24: 257-265.

131. Lye HS, Kuan CY, Ewe JA, Fung WY, Liong MT. The improvement of hypertension by probiotics: Effects on cholesterol, diabetes, renin, and phytoestrogens. International Journal of Molecular Sciences 2009; 10(9): 37553775. PMID:19865517. 